\title{
Perceived brightness as a function of flash duration in the peripheral visual field
}

\author{
NAOYUKI OSAKA \\ Kyoto University, Kyoto 606, Japan
}

\begin{abstract}
Using a method of direct magnitude estimation, perceived brightness was measured in the dark-adapted eye with brief flashes of varying duration (1-1,000 msec), size (16'-116'), and retinal loci $\left(0^{\circ}-60^{\circ}\right)$ for the lower photopic luminance levels covering the range between 8.60 and $.86 \mathrm{~cd} / \mathrm{m}^{2}$ in steps of $.5 \mathrm{log}$ units. Perceived brightness increased as a function of flash duration as well as luminance up to approximately $100 \mathrm{msec}$, then remained constant above $100 \mathrm{msec}$. The enhancement of brightness at about a $50-\mathrm{msec}$ flash duration has been observed not in the fovea but in the periphery. Target size also has been found to be effective on brightness.
\end{abstract}

It has been established in threshold studies as Bloch's law that luminance power is integrated over time up to a critical duration of approximately $100 \mathrm{msec}$, beyond which temporal summation ceases and the threshold is then defined solely in terms of target luminance. This reciprocity law (luminance $x$ time $=$ constant) has been known to hold up to critical duration. At suprathreshold levels, in general, a similar relationship still holds, whereas some curious nonlinear overshooting, i.e., enhancement of perceived brightness near critical duration, has also been observed at a relatively higher photopic luminance range (Aiba \& S. S. Stevens, 1964; Broca \& Sulzer, 1902; Ekman, 1966; Katz, 1964; Marks, 1974; Raab, 1962; J. C. Stevens \& Hall, 1966; S. S. Stevens \& J. C. Stevens, Note 1). At higher photopic luminance levels (above $11.15 \mathrm{~cd} / \mathrm{m}^{2}$ ), Raab (1962) found that the brightness overshooting effect was maximal in the neighborhood of 50 msec in the darkadapted eye. Similarly, Aiba and S. S. Stevens (1964) showed that the temporal locus of this peak of overshooting hump tended to shift from approximately 300 to $30 \mathrm{msec}$ as a function of increasing target luminance in the dark-adapted eye. In a similar way, Arend (1973) and J. C. Stevens and Hall (1966) confirmed these results.

In cone-dominated foveal viewing, the overshooting effect, known as the photopic Broca-Sulzer effect (Broca \& Sulzer, 1902), has been observed only at relatively higher photopic luminance levels up to about $6,500 \mathrm{~cd} / \mathrm{m}^{2}\left(98 \mathrm{~dB} \mathrm{re} 10^{-6} \mathrm{~cd} / \mathrm{m}^{2}\right.$ ) (Aiba \& S. S. Stevens, 1964; Raab, 1962; J. C. Stevens \& Hall, 1966').

On the other hand, in rod-dominated peripheral viewing, White, Collins, and Rinalducci (1976), using a two-color procedure, recently obtained the Broca-

Thanks are due Professor S. Kakizaki for his critical readings of the manuscript.
Sulzer effect under a scotopic viewing condition in the parafovea $\left(1^{\circ}\right.$ target presented via Maxwellian optics to $7^{\circ}$ eccentric to the fovea). Interestingly enough, the scotopic Broca-Sulzer effect reached a maximum between 200 and $400 \mathrm{msec}$, which, contrary to the photopic effect, showed a shift toward longer flash durations as a function of increasing retinal illuminance of the standard.

Therefore, it should be noted that the differences between the scotopic Broca-Sulzer effect and the photopic effect are due to retinal eccentricity from the fovea (White et al., 1976). Moreover, the BrocaSulzer effect was also found between 70 and $100 \mathrm{msec}$ at an eccentricity of $9^{\circ}$ under photopic viewing conditions (Baumgardt, 1963).

Although the effect of flash duration on perceived brightness has been investigated for a single retinal position, a systematic comparison among different retinal locations in an extended visual field has not yet been investigated. The dependence of perceived brightness on flash duration was investigated in the present study under the dark-adapted eye, with photopic luminance (Experiment 1) and target size (Experiment 2) varied parametrically, in an extended visual field from the fovea up to the far periphery.

\section{EXPERIMENT 1}

The effect of luminance on perceived brightness was investigated in the fovea and in the periphery.

\section{Method}

Subjects. Sixteen subjects (15 male and 1 female graduate students), who had normal or corrected-to-normal vision, served as subjects. All had previously served in a similar experiment of magnitude estimation.

Apparatus. A Sylvania glow modulator tube (R1131C) with rise and fall times shorter than $.01 \mathrm{msec}$ was mounted in the lamp housing as a light source. A regulated power supply furnished $350 \mathrm{~V}$ dc to the glow tube with current output maintained at 
$30 \mathrm{~mA}$. The light was collimated, passed through neutral density filters and a circular aperture, and the circular target was projected on the hemispherical white diffusing plane of a projection perimeter (Handaya, Model HE-130) which includes optical systems for projecting target and fixation fields. The inner plane of the perimeter was coated with white diffusing material, which eliminated cues for target location. Targets could be presented to any peripheral location on the nasal side of the fovea. Using a square pulse generator (Nihon Kohden, Model MSE-3), seven target durations were used: $1,5,10,50,100,500$, and $1,000 \mathrm{msec}$.

Luminance of the white target was changed by means of Kodak Wratten No. 96 neutral density filters in the optical path of the light. Three lower photopic luminances were used, covering the range between .86 and $8.60 \mathrm{~cd} / \mathrm{m}^{2}$ in steps of $.5 \mathrm{log}$ units. Target luminance was measured using a photometer (Sanso, Model 12A). The size of the target was set at $44^{\prime}$ visual angle. Four retinal locations along the horizontal meridian of the right eye were investigated: fovea and $20^{\circ}, 40^{\circ}$, and $60^{\circ}$ nasally eccentric to the fovea. The blind spot was carefully avoided.

The fixation field consisted of a diamond-shaped array of four dots of dark red light which was adjusted to be just visible by means of Wratten No. 29 filters and which subtended a visual angle of $120^{\prime}$ diagonally.

The subject's head was rested on a chin support which was set the subject's right eye at a $32-\mathrm{cm}$ viewing distance.

Procedure. After wearing red goggles for $5 \mathrm{~min}$, the subject entered the dark chamber for $10 \mathrm{~min}$ of dark adaptation. The subject viewed the target with the right eye, and the left eye was occluded with an eyepatch.

Twenty-one stimuli were each presented in succession for each of the four retinal loci. Each target was presented twice in an experimental session in counterbalanced sequence. Thus, each subject performed a total of 3 by 7 by 4 (i.e., combinations of luminance, duration, and retinal locus, respectively) by 2 trials. The order of presentation was randomized for each subject and session. The method of direct magnitude estimation was used. Brightness of modulus was a foveal standard stimulus $(10 \mathrm{msec}$ duration, $2.70 \mathrm{~cd} / \mathrm{m}^{2}$ ) called " 10 ," presented after every 10 trials and, in addition, whenever the subject asked to see the modulus. The subjects presented the target to themselves. The self-pacing technique employed here was similar to that employed by Raab (1962). The subject was asked to give the comparison target any number that seemed to him most appropriate to stand for the perceived brightness in proportion to the perceived brightness of the modulus, ignoring as much as possible any differences in perceived flash duration. If the subject felt that he had not seen a given flash properly, he could ask for another presentation. The time between stimulus presentations was approximately $20 \mathrm{sec}$.

\section{Results and Discussion}

The log geometric mean of 16 subjects' brightness estimates (total of 32 judgments per each condition) for each luminance is plotted against log flash duration in Figure 1 for the three different retinal loci in the periphery and in the fovea. The lines in Figure 1 were fitted by eye.

In foveal viewing, perceived brightness increased as a function of flash duration up to approximately 50-100 msec, beyond which the perceived brightness was defined solely in terms of luminance. In peripheral viewing, perceived brightness increased as a function of flash duration up to approximately $50 \mathrm{msec}$, beyond which the perceived brightness was not dependent on flash duration, but on luminance. These results are in good agreement with the data by
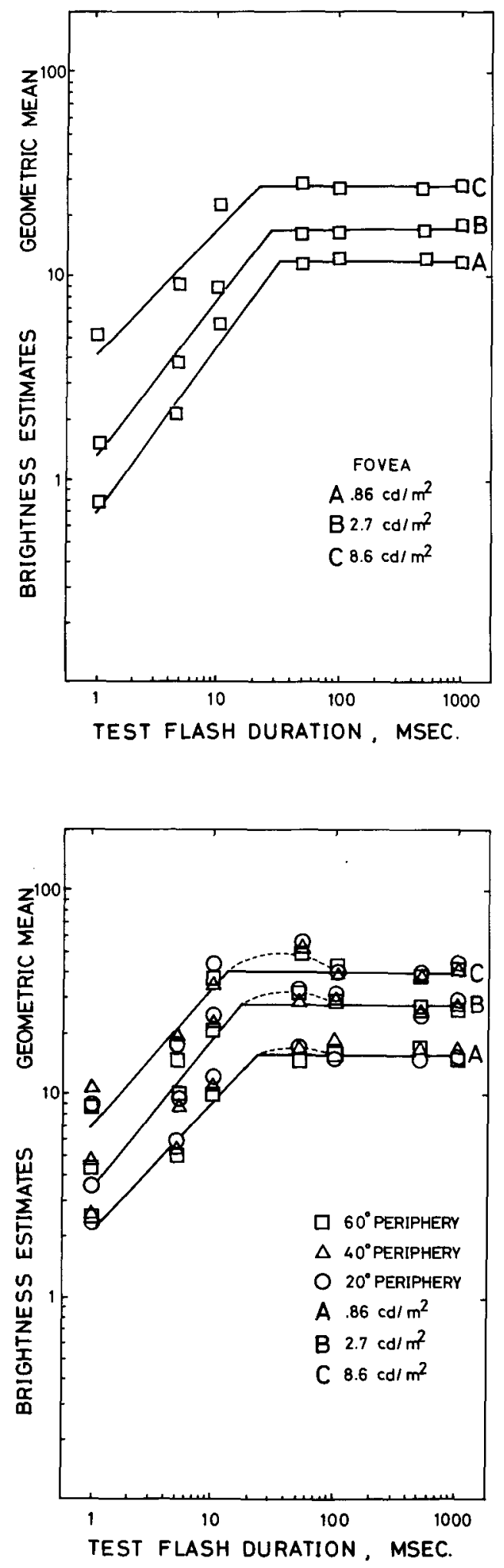

Figure 1. Perceived brightness as a function of flash duration at three levels of peak luminance in the foveal and peripheral viewing conditions. The parameter is luminance in $\mathrm{cd} / \mathrm{m}^{2}$. 
Aiba and S. S. Stevens (1964), Raab (1962), and J. C. Stevens \& Hall (1966). In Figure 1, there usually occurs an enhancement (shown by the dotted humps) in the region of the critical duration. It was found that, in peripheral viewing, perceived brightness was independent of retinal locus: no systematic difference was found among three different retinal loci investigated $\left(20^{\circ}, 40^{\circ}\right.$, and $60^{\circ}$ nasally eccentric to the fovea). Both the slope and the spacing of the function in a given plot were approximately equal over the shorter durations, as expected from Bloch's law. The data plot in Figure 1 provides some checks on this reciprocity law. Considering the data points at $50 \mathrm{msec}$ and less, the plot provides only two equalenergy pairs of stimulus (i.e., $8.60 \mathrm{~cd} / \mathrm{m}^{2}$ at $1 \mathrm{msec}$ and $.86 \mathrm{~cd} / \mathrm{m}^{2}$ at $10 \mathrm{msec} ; 8.60 \mathrm{~cd} / \mathrm{m}^{2}$ at $5 \mathrm{msec}$ and $.86 \mathrm{~cd} / \mathrm{m}^{2}$ at $50 \mathrm{msec}$ ). Further inspection of Figure 1 reveals that the mean brightnesses of the shorter flash $(1 \mathrm{msec})$ and longer flash $(10 \mathrm{msec})$ with equal-energy were about 5.25 and 5.89 in the fovea and about 9.21 and 11.00 in the periphery (averaged over three retinal loci), respectively. Similarly, mean brightnesses of the shorter flash $(5 \mathrm{msec})$ and the longer flash $(50 \mathrm{msec})$ with equalenergy were about 8.92 and 10.96 in the fovea and about 16.07 and 17.00 in the periphery, respectively. It was thus confirmed that within the region of temporal integration, two such equal-energy flashes were judged as equally bright, as predicted from Bloch's law.

In both viewing conditions, perceived brightness increased as a function of increasing target luminance. It is likely that the duration where the brightness-ceases to increase shifted toward the shorter durations. These results are also in good agreement with the results obtained by several other investigators (Aiba \& S. S. Stevens, 1964; Mansfield, 1973; Marks, 1974; Raab, 1962; J. C. Stevens \& Hall, 1966). It is, however, evident that a target of a given luminance was judged brighter when it was presented in the periphery than when it was presented in the fovea. This superiority of the periphery over the fovea is evident at shorter flash durations. Although Pöppel and Harvey (1973) found that a target with a given luminance appeared equally bright at several retinal loci, this peripheral superiority was also reported by Marks (1971) and Osaka (1975) in steady-state longer flash durations (between 1 and $2 \mathrm{sec}$ ) under the dark-adapted eye (however, the reverse relationship was the case for the light-adapted eye (Marks, 1968)]. In addition, brightness enhancement could be observed only at a flash duration of $50 \mathrm{msec}$ in the peripheral viewing, whereas no such an enhancement was observed in the foveal viewing. At similar luminance levels, several studies (Aiba \& S. S. Stevens, 1964; Raab, 1962; J. C. Stevens \& Hall, 1966) showed a slight enhancement in the foveal vision. This disagreement with the present results may be partly due to difference of target size.

The data were plotted in a different way in Figure 2, where the log geometric means of the brightness for target with luminance between .86 and $8.60 \mathrm{~cd} / \mathrm{m}^{2}$ were replotted as a function of luminance with target duration as the parameter: i.e., it was fitted by a function of the form, $\psi=k \phi^{\beta}$, where $\psi, \phi, \beta$, and $\mathrm{k}$ represent perceived brightness, luminance, exponent, and a scale factor, respectively. ${ }^{2}$ Straight lines were fitted by the method of least squares.

The exponent $\beta$, the slope of each function in Figure 2, is plotted as a function of flash duration in Figure 3. As shown in Figure 3, the flash duration increases as the exponent decreases. The exponent in the foveal viewing decreased linearly down to $100 \mathrm{msec}$, beyond which the exponent maintained a steady-state exponent of about .33. On the other hand, the exponent in the periphery remained around .50 between 1 and $50 \mathrm{msec}$, then decreased, and then again maintained the value of about .40. These exponents as a function of flash duration were somewhat different from those obtained by some other studies (Raab, 1962; J. C. Stevens \& Hall, 1966): At shorter durations, the present exponents are considerably larger in the foveal viewing. However, mean exponents for shorter flashes (.62 and .50 for the fovea and the periphery, respectively) and for longer flashes (.33 and .39 for the fovea and the periphery, respectively) were found to be similar to those of other studies, since the exponent was about half again as large for short durations as for long (Mansfield, 1973; Raab, 1962; J. C. Stevens \& Hall, 1966). Furthermore, of particular interest in these results was that, at the longest duration $(1 \mathrm{sec})$, the peripheral exponent $(.43)$ was about .10 larger than that of foveal exponent (.33). It is

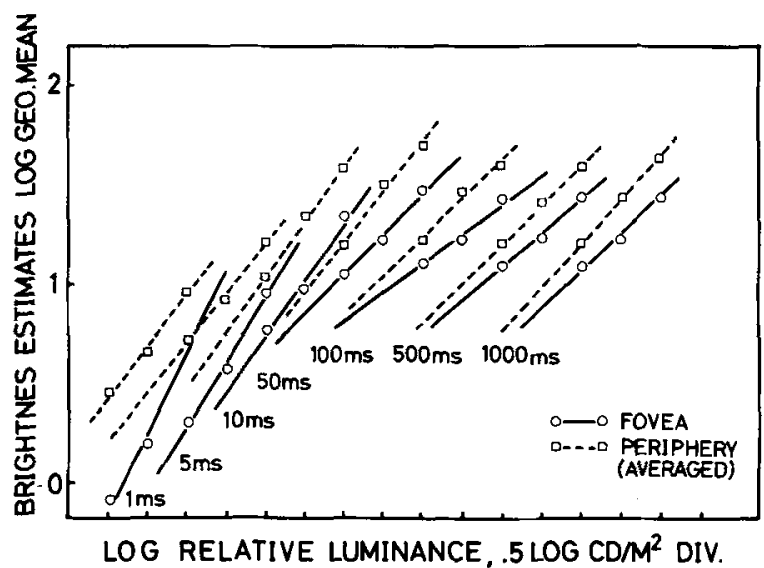

Figure 2. Perceived brightness as a function of relative luminance for seven different flash durations in foveal and peripheral viewing. The parameter is flash duration in milliseconds. 


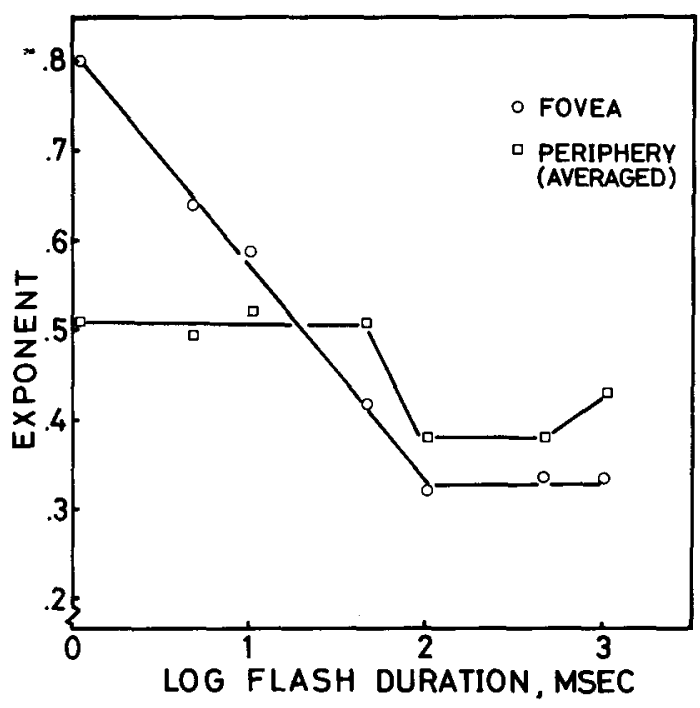

Figure 3. Exponents of the brightness power function shown in Figure 2 as a function of flash duration in foveal and peripheral viewing. Exponents for the periphery were averaged since little difference was found.

puzzling and interesting that Drum (1976) found a significant increase of exponent as a function of increasing retinal locus, while no such an enhancement was found among peripheral loci in these results. $^{3}$

\section{EXPERIMENT 2}

The effect of target size on perceived brightness was investigated in the fovea and in the periphery.

\section{Method \\ Subjects. Twelve subjects (eight male and four female graduate students), who had normal or corrected to normal vision, served as subjects. Half of them had served in Experiment 1. \\ Apparatus. The apparatus were the same as used in Experi- ment 1 , with the following differences. Ten target durations were used: $1,2,5,10,20,50,100,200,500$, and $1,000 \mathrm{msec}$. The size of the target was varied by circular apertures which provided four visual angles: $16^{\prime}, 44^{\prime}, 69^{\prime}$, and $116^{\prime}$. Three retinal locations were explored: fovea and $30^{\circ}$ and $60^{\circ}$ nasally eccentric to the fovea. Luminance of the target was fixed at $2.70 \mathrm{~cd} / \mathrm{m}^{2}$. \\ Procedure. The procedure used was the same as that used in Experiment 1, with the following differences. Forty stimuli were each presented in succession for each of the three retinal locations. Trials were replicated twice, in random order, for each condition. Thus, each subject performed a total of 4 by 10 by 3 by 2 trials. The order of presentation was randomized. The perceived bright- ness of the foveally presented modulus (10 msec duration, 44' target size) was called " 10. ."}

\section{Results and Discussion}

In Figure 4, the log geometric mean of 12 subjects' brightness estimates (total of 24 judgments per each condition) for each target size is plotted as a function of $\log$ flash duration for three different retinal loci (fovea, $30^{\circ}$ and $60^{\circ}$ nasal). Although Drum (1976) and Marks (1971) found that there was relatively little effect of size on equal brightness curves at flash durations of .5 and $1 \mathrm{sec}$, respectively, Osaka (1975) found that there was some effect of size on brightness. It should also be noted that brightness decreased with increasing target size (spatial BrocaSulzer effect), with small target size between $3^{\prime}$ and $6^{\prime}$ at the higher suprathreshold levels (Higgins \& Rinalducci, 1975a, 1975b). Again, in the present experiment, the effect of target size on perceived brightness is clearly shown in Figure 4 . In both foveal and peripheral viewing conditions, size had enough effective influence on brightness over three $\log$ units flash region. Although the smallest size (16') was less effective on brightness than the other larger targets in the periphery, perceived brightness increased as a function of increasing target size except for the longer flash for $60^{\circ}$ periphery.

In both foveal and peripheral viewing conditions, perceived brightness increased as a function of flash duration up to approximately $20-100 \mathrm{msec}$, beyond which the brightness was defined solely in terms of luminance as well as target size. Further inspection of Figure 4 shows that, similar to the results of Experiment 1 , perceived brightness was judged less bright in foveal viewing than in peripheral viewing. As flash duration decreased, this peripheral superiority over the fovea considerably increased. This can be estimated from the steep slopes in the foveal viewing between the 50 - and 1-msec flash durations. The results obtained by Arend (1973) showed that the brightness enhancement effect was not obtained when the contours of the target were heavily blurred. This implies that some spatial factors, rather than temporal factors (Boynton, 1961), are important if the enhancement originates in the framework of simultaneous contrast (Corwin \& Giambalvo, 1974). Brightness enhancement (shown by the dotted humps in Figure 4) can also only be observed at flash durations of $50-100 \mathrm{msec}$ in the peripheral viewing, whereas no such an enhancement was observed in the foveal viewing. This result was puzzling since a target presented peripherally might have some blurring (out of focus) because of refractive error as well as lateral spherical aberration due to oblique incidence of the target light (Osaka, 1977).

\section{GENERAL DISCUSSION}

In both experiments ( 1 and 2$)$, the brightness enhancement was observed uniquely in peripheral viewing. This can be partly explained in terms of different underlying mechanisms for brightness perception in the fovea and in the periphery. The recently reported sustained/transient, or $\mathrm{X}$ and $\mathrm{Y}$, channels (Breitmeyer \& Ganz, 1976; Enroth-Cugell \& Robson, 1966; Ikeda \& Wright, 1972a, 1972b) which are supposed to have an underlying physio- 

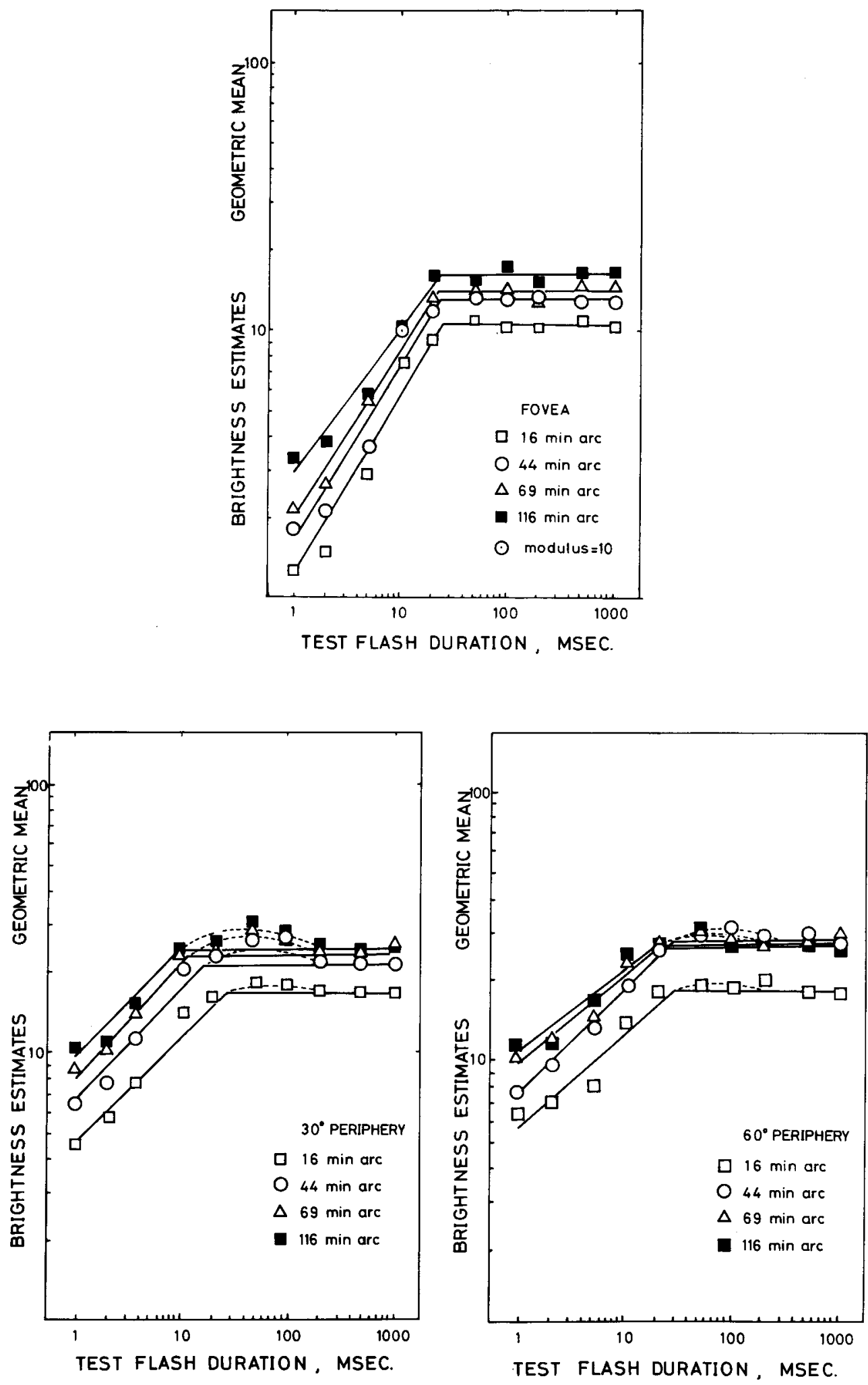

Figure 4. Perceived brightness as a function of flash duration at four different target sizes in the foveal and peripheral viewing. 
logical mechanism in the human visual system may be closely related to such an enhancement effect. These functional channels are based on classification of retinal ganglion cells in which transient cells respond transiently (differentially) to the step change of a luminous spot, whereas sustained cells respond in a sustained manner (integratively) to the onset (and offset) of the spot. Furthermore, sustained/ transient channels roughly correspond to the foveal/ peripheral visual systems, respectively. This trend for transient neurons to increase and for sustained neurons to decrease with retinal eccentricity is still maintained at the striate cortex (Breitmeyer \& Ganz, 1976; Ikeda \& Wright, 1975). Furthermore, transient cell receptive fields increase in size with increasing retinal eccentricity. During the present experiment, several subjects verbally reported that flashes of the same duration appeared crisp, sharp, and of relatively short duration in the periphery, while flashes appeared to have softer quality and to remain for longer durations in the fovea. Thus, it would seem reasonable to expect the sustained-foveal channel to be luminance-dependent and the transient-peripheral channel to be time-dependent on the flash of light. It may be interesting to compare simultaneously the perceived brightness in the fovea with that in the periphery when the experiment is done in the uniformly illuminated Ganzfeld (i.e., the largest target size).

\section{REFERENCENOTE}

1. Stevens, S. S., \& Stevens, J. C. The dynamics of visual brightness. Psychophysical project, Harvard University, 1960.

\section{REFERENCES}

Aiba, T. S., \& Stevens, S. S. Relation of brightness to duration and luminance under light- and dark-adaptation. Vision Research, 1964, 4, 391-401.

AREND, L. E., JR. Spatial factors in the Broca-Sulzer phenomenon. Journal of the Optical Society of America, 1973, 63, 879-883.

BAUmgardT, E. La phénomène de Broca et Sulzer en vision périphérique. Comptes Rendus des Séances de la Société de Biologie, 1963, 157, 506-509.

Boynton, R. M. Some temporal factors in vision. In W. A. Rosenblith (Ed.), Sensory communication. New York: MIT Press, 1961. Pp. 739-756.

BreitMeYer, B. G., \& GANz, L. Implications of sustained and transient channels for theories of visual pattern masking, saccadic suppression, and information processing. Psychological Review, 1976, 83, 1-36.

Broca, A., \& Sulzer, D. La sensation lumineuse en fonction du temps. Comptes Rendus de Séances des liAcadémie des Sciences, 1902, 134, 831-834.

Corwin, T. R., \& Giambalvo, V. Effects of simultaneous contrast on temporal brightness enhancement. American Journal of Optometry and Physiological Optics, 1974, 51, 175-180.

DRUM, B. The relation of apparent brightness to contrast threshold on a photopic background: Dependence on retinal position and target size. Vision Research, 1976, 16, 1401-1406.

Ekman, G. Temporal integration of brightness. Vision Research, $1966,6,683-688$
Enroth-Cugell, C., \& Robson, J. G. The contrast sensitivity of retinal ganglion cells of the cat. Journal of Physiology, 1966, 187, 517-552.

Higgins, K. E., \& Rinalducci, E. J. Suprathreshold intensityarea relationships: A spatial Broca-Sulzer effect. Vision Research, $1975,15,129-143$. (a)

Higgins, K. E., \& Rinalducci, E. J. The spatial Broca-Sulzer and sensitization effects for foveal viewing. Vision Research, $1975,15,423-425$. (b)

IKEDA, H., \& WRIGHT, M. J. Differential effects of refractive errors and receptive field organization of central and peripheral ganglion cells. Vision Research, 1972, 12, 1465-1476. (a)

IKEDA, H., \& WRIGHT, M. J. Receptive field organization of "sustained" and "transient" retinal ganglion cells which subserve different functional roles. Journal of Physiology, 1972, 227, 769-800. (b)

IKEDA, H., \& WRIGHT, M. J. Retinotopic distribution, visual latency and orientation tuning of "sustained" and "transient" cortical neurones in area 17 of the cat. Experimental Brain Research, 1975, 22, 385-398.

KaTz, M. S. Brief flash brightness. Vision Research, 1964, 4, 361-373.

Mansfield, R. J. W. Brightness function: Effect of area and duration. Joumal of the Optical Society of America, 1973, 63, 913-920.

Marks, L. E. Brightness as a function of retinal locus in the light-adapted eye. Vision Research, 1968, 8, 525-535.

Marks, L. E. Brightness and retinal locus: Effects of target size and spectral composition. Perception \& Psychophysics, 1971, 9, 26-30.

Marks, L. E. Sensory processes: The new psychophysics. New York: Academic Press, 1974.

Os AKA, N. Target size and luminance in apparent brightness of the peripheral visual field. Perceptual and Motor Skills, 1975, 41, 49-50.

Osaka, N. Effect of refraction on perceived locus of a target in the peripheral visual field. Journal of Psychology, 1977, 95, 59-62.

PöPPEl, E., \& Harvey, L. O., JR. Light-difference threshold and subjective brightness in the periphery of the visual field. Psychologische Forschung, 1973, 36, 145-161.

RAAB, D. Magnitude estimation of brightness of brief foveal stimuli. Science, $1962,135,42-43$.

Stevens, J. C., \& Hall, J. W. Brightness and loudness as functions of stimulus duration. Perception \& Psychophysics, $1966,1,319-327$.

White, T. W., Collins, S. B., \& Rinalducci, E. J. The Broca-Sulzer effect under scotopic viewing conditions. Vision Research, 1976, 16, 1439-1443.

\section{NOTE}

1. Using the dark-adapted eye, both experiments carried out by Raab (1962) and J. C. Stevens and Hall (1966) failed to find such an enhancement of perceived brightness at the topmost photopic levels of $955 \mathrm{~cd} / \mathrm{m}^{2}\left(90 \mathrm{~dB}\right.$ re $\left.10^{-6} \mathrm{~cd} / \mathrm{m}^{2}\right)$ and $9,554 \mathrm{~cd} / \mathrm{m}^{2}$ (100 dB re $10^{-6} \mathrm{~cd} / \mathrm{m}^{2}$ ), respectively, where Aiba and S. S. Stevens (1964) obtained the enhancement at a level of $6,369 \mathrm{~cd} / \mathrm{m}^{2}(98 \mathrm{~dB}$ re $10^{-6} \mathrm{~cd} / \mathrm{m}^{2}$ ). These discrepancies in the results can be explained in terms of differences in methodology employed in each study: First, Raab (1962) and J. C. Stevens and Hall (1966) used a method of direct magnitude estimation, while Aiba and S. S. Stevens (1964) used an interocular matching procedure. Secondly, it was likely that the effect of size (Osaka, 1975) might play a critical role on brightness enhancement in a way that accounts for the results, since Raab (1962) and J. C. Stevens and Hall (1966) employed targets subtending $35^{\prime}$ and $123^{\prime}$ in size, respectively while the largest size employed by Aiba and S. S. Stevens (1964) was $240^{\prime}$ in visual angle.

2. If brightness estimates for equal-energy flashes were averaged in the Bloch region (less than $50 \mathrm{msec}$ ), log brightness estimates 
would increase as a function of log relative luminous-energy (duration $\times$ luminance): In a $\log -\log$ plot, the function can be described by the form, $\psi=\mathrm{kE}^{\alpha}$, where $\mathrm{E}, \alpha$, and $\mathrm{k}$ show luminousenergy, exponent, and a scale factor (Mansfield, 1973), respectively. Calculation of $\alpha$ and $\mathbf{k}$, by a method of least squares, showed .35 and 2.50 for the fovea but .30 and 5.12 for the periphery, respectively.

3. In the present results (1-sec condition), exponents of .44
$(.996) .+3(.899)$, and $.43(.999)$ were found for $20^{\circ}, 40^{\circ}$, and $60^{\circ}$. respectivelyoduct moment correlation coefficients are shown in parenthesis). Thus, no significant difference was found among peripheral loci.

(Received for publication January 17, 1977; revision accepted May 2, 1977.) 